\title{
Corpolítica: Coletiva e Projeto de Extensão LGBT. Extensão Popular e Guerrilha Estético- Política de Vivências LGBT ${ }^{*}$
}

DOI: https://10.18046/recs.i32.3772

\begin{abstract}
Body Politics: Collective and LGBT Extension Project. Popular Extension and Aesthetic-Political Guerrilla in LGBT Experiences
\end{abstract}

Corpolitica: colectiva y proyecto de extensión LGBT. Extensión popular y guerrilla estético-politica de vivencias LGBT

\author{
Evandro Piza-Duarte ${ }^{* *}$ \\ Universidade de Brasília (Brasília, Brasil) \\ Gabriel Santos-Pereira ${ }^{* * *}$ \\ Universidade de Brasília (Brasília, Brasil) \\ Gustavo Costa ${ }^{* * * *}$ \\ Universidade Federal da Paraíba (João Pessoa, Brasil) \\ J. C. Oliveira ${ }^{* * * * *}$ \\ Universidade de Brasília (Brasília, Brasil) \\ Maria Léo Araruna ${ }^{* * * * * *}$ \\ Universidade de Brasília (Brasília, Brasil)
}

\footnotetext{
* O Projeto "Corpolítica: diálogos sobre gênero, sexualidade, raça e direitos com jovens em espaços urbanos periféricos no Distrito Federal", encontra-se registrado como projeto de extensão na Universidade de Brasília, porém não contou com nenhum financiamento direto. Este trabalho foi poduzido durante um estágio visita apoiado pelo Programa de Cooperação Internacional CAPES/COFECUB na Universidade da Pensilvânia, no Centro de Estudos Populacionais (The Population Studies Center [PSC]) com o professor PhD Tukufu Zuberi, financiado pela CAPES (Coordenação de Aperfeiçoamento de Pessoal de Nível Superior com o Ministério da Educação brasileiro, proc.n. 88881.19917/2016-1). Artigo de pesquisa recebido em 26.10.2018 e aceito em 01.01.2020.
} 
** Professor de Direito Processual Penal e Criminologia na Faculdade de Direito da Universidade de Brasília (Brasil). Mestre em Direito pela UFSC e Doutor em Direito pela UnB. Autor de Criminologia e Racismo. Curitiba: Juruá, 2017. Email: evandropiza@gmail.com ORCID: https://orcid.org/oooo-0oo2-0077-0297

*** Estudante de Ciência da Computação na Universidade de Brasília (Brasil), bicha preta não binária, pansexual e ativista do movimento negro e LGBTI, atua na União Libertária de Pessoas Trans e Travestis (ULTRA) e na coletiva Corpolítica. Email: gabrielsp-g13@hotmail.com ORCID: https://orcid.org/oooo-ooo2-3858-385X

**** Mestrando em Direitos Humanos, Cidadania e Políticas Públicas na Universidade Federal da Paraíba (Brasil), graduado em Gestão de Políticas Públicas pela Universidade de Brasília (UnB), bissexual, ativista LGBT na Corpolítica. Email: gustavosouza8@gmail.com ORCID: https://orcid.org/oooo-ooo3-0637-7565

${ }^{* * * * *}$ Mestranda em Direito pela Universidade de Brasília (Brasil), bacharel em Direito pelo Centro Universitário Planalto do Distrito Federal (UNIPLAN), colabora na defesa criminal da Defensoria Pública do Distrito Federal, bicha preta não binária, atua na coletiva Corpolítica.Email:jefersoncardosooliveira@gmail.com ORCID:https://orcid.org/oooo-ooo2-2187-4618

***** Graduanda em Direito na Universidade de Brasília, travesti, atriz, performer, escritora e militante da coletiva Corpolítica. Email: leoararuna27@gmail.com ORCID: https://orcid.org/oooo-ooo2-4497-1162

\section{Cómo citar/How to cite}

Piza-Duarte, Evandro; Santos-Pereira, Gabriel; Costa, Gustavo; Cardoli, Jefie; Araruna, Maria Léo (2020). Corpolítica: Coletiva e Projeto de Extensão LGBT. Extensão Popular e Guerrilha Estético-Política de Vivências LGBT. Revista CS, 32, 163-189. DOI: https://10.18046/recs.i32.3772 
O texto trata das relações entre a experiência de extensão de uma coletiva LGBTI+, caracterizada pela interseccionalidade, e o poder heterocisnormativo na universidade. Relata as experiências de ensino, pesquisa e extensão do Projeto "Corpolítica" que foram construídas desde a perspectiva de uma Coletiva LGBT de mesmo nome, criada na Universidade de Brasília (UnB) em 2014. Do ponto de vista metodológico, utiliza-se da memória compartilhada, da análise documental, entrevistas etc. Propõe a reflexão sobre o lugar marginal dessa produção e a impossibilidade de, efetivamente, ocupar as posições hegemônicas, sugerindo a utilização do termo "guerrilha" como categoria compreensiva dessas estratégias. Interroga os atuais modelos de Extensão Popular, ao demonstrar que a extensão pode também reproduzir dimensões de poder da "matriz heterossexual" (Judith Butler) ou investir numa sociabilidade afetiva de (des)construção das formas tradicionais de saber, sempre marcada pelo lugar de precariedade das sujeitas envolvidas e pela efemeridade das experiências nos espaços universitários.

\section{PALAVRAS-CHAVE:}

Educação, Extensão Universitária, Discriminação, Sexualidade, Raça

This paper addresses the teaching, research, and outreach experiences of an LGBTI+ collective's outreach project called "Corpolítica" (body politics), which was created in the University of Brasília (UnB) in 2014. The fundamental reflection analyses the cisgender and heteronormative power that structures the university, characterized by its intersectional approach. The methods used in this paper are: shared memory, document analysis, interviews, etc. The aim is to reflect on the peripheral space of this production and the impossibility of effectively occupy hegemonic positions, suggesting the use of the term "guerrilla" as a comprehensive category of those strategies. This paper also questions the current models of popular outreach, as it shows that outreach can also reproduce power dimensions of the "heterosexual matrix" (Judith Butler), or invest in an effective sociability of (de)construction of traditional forms of knowledge, always marked by the precarious situation of the subjects involved and the momentary experiences in the university sphere.

\section{KEYWORDS:}

Education, Outreach Experiences, Discrimination, Sexuality, Race 
El texto relata diversas experiencias de enseñanza, investigación y extensión del proyecto "Corpolítica: diálogos sobre género, sexualidad, raza y derechos con jóvenes en espacios urbanos periféricos en el Distrito Federal", que fueron construidas desde la perspectiva de una Colectiva LGBTI+ del mismo nombre. La reflexión central aborda las relaciones entre la experiencia de extensión de la colectiva, caracterizada por la interseccionalidad, y el poder heterocisnormativo en la Universidad. Desde el punto de vista metodológico, utiliza diversas estrategias: memoria compartida, análisis documental, entrevistas, etc. Propone la reflexión sobre el lugar marginal de esa producción y la imposibilidad de, efectivamente, ocupar las posiciones hegemónicas, lo que sugiere la utilización del término guerrilla. El texto interroga a los actuales modelos de extensión popular al demostrar que la extensión puede también reproducir dimensiones de poder de la matriz heterosexual (Judith Butler) o invertir en una sociabilidad afectiva de (de)construcción de las formas tradicionales de saber, siempre marcada por el lugar de precariedad de las involucradas y de lo efímero de las experiencias en los espacios universitarios.

PALABRAS CLAVE:

educación, extensión universitaria, discriminación, sexualidad, raza 


\section{Introdução}

O texto apresenta um conjunto de experiências relacionadas ao ensino, à pesquisa e à extensão do Projeto de Extensão « Corpolítica: diálogos sobre gênero, sexualidade, raça e direitos com jovens em espaços urbanos periféricos no Distrito Federal" ${ }^{1}$. O projeto foi constituído com participação de Lésbicas, Gays, Bissexuais, Travestis, Transexuais e Não binárias (LGBT+). Além do projeto de extensão, as pessoas envolvidas comporam também uma coletiva com o mesmo nome. A atividade da Coletiva Corpolítica excede os limites do projeto de extensão, porém, relacioná-las é importante para compreender as dinâmicas de sua constituição no espaço universitário e considerar eventuais especificidades da Extensão LGBT diante das práticas de Extensão Popular². Nesse propósito, o texto busca descrever e compreender as dinâmicas entre práticas de extensão e demandas de estudantes LGBT a partir dessa experiência iniciada em 2014 .

A prática de extensão LGBT está ausente na literatura ${ }^{3}$ por se tratar de fenômeno recente ou em razão das redes acadêmicas constituídas desde o poder heterocisnormativo ${ }^{4}$. Cassal e Zucco (2010), ainda centrados nos estudos sobre a violência

1. Escrevemos este texto em diversos momentos de parceria. Inicialmente, surgiu a necessidade de elaborar o Projeto de Extensão em 2016 para submeter à Universidade de Brasília. Nesse momento, o Coordenador do Projeto de Extensão, Evandro Piza Duarte, colaborou com as alunas Maria Léo Araruna, Rebecca Religare e Mariana Mota. Posteriormente, escrevemos juntas, com Jefie Cardoli e Gabriel Santos Pereira, uma primeira versão para o III Colóquio Luso-brasileiro sobre Questões Curriculares (2017). Depois retomamos o processo de escrita com as demais autoras para essa esta versão. Todas estas essas etapas inspiraram esse este texto.

2. Embora o texto não se ocupe de outras coletivas e grupos LGBT, estão ativas na Universidade de Brasília, entre outras: Rexistir (Núcleo LGBT da UnB, estruturado como Centro de Resistência e Conscientização e Observatório Jurídico) e Escuta Diversa (Rede de proteção para a comunidade LGBT da UnB).

3. Em consulta a bases de dados acadêmicos, com os termos "extensão" e "LGBT", foi possível identificar apenas três artigos: a) scielo (www.scielo.org), nenhum; b) periódicos CAPES (www.periodicos.capes. gov.br), o1; no Google Acadêmico (scholar.google.com.br), 02.

4. Por heterocisnormatividade, entende-se os sistemas de poder que regulam os indivíduos (essencialmente através da sociabilização, mas não apenas dela) a fim de manter uma estrutura de poder que privilegia pessoas heterossexuais e cisgêneras. O regime da cisgeneridade "se refere à necessidade de alinhamento entre "sexo biológico" e "gênero", ou seja, a definição do gênero de alguém precisa estar ligada a um certo critério objetivo e estável construído historicamente que é o do dimorfismo sexual. Assim, não deveria haver equívocos nas definições "macho/homem" e "fêmea/mulher". Além disso, é preciso dizer que a cisnormatividade estrutura as relações sociais e, por conseguinte, marginaliza e violenta aquelas pessoas (trans) que não seguem seus pressupostos (Vergueiro, 2016: 57). Essa cisgeneridade, está associada a heteronorma da seguinte forma: "A socialização de gênero é desde sempre o aculturamento para a cisgeneridade. A masculinidade - o papel esperado para indivíduos aculturados para serem 'homens' - e a feminilidade - o papel esperado para indivíduos aculturados para serem 'mulheres' - não existe fora dos 
LGBT fóbica no ambiente escolar, relatam a experiência de interação entre o projeto "Diversidade Sexual na Escola" para professoras da rede pública que é promovido por estudantes da Universidade Federal do Rio de Janeiro (UFRJ). Por sua vez, Reis, Dias e Benitez, (2016) e Lionço, Tavira, Baére e Portela (2016) aproximam-se dos estudos sobre a violência LGBTfóbica nas escolas para compreender experiências de extensão que se passam no ambiente universitário. As primeiras relatam o projeto "Una-se Contra a LGBTfobia", no Centro Universitário Una (Belo Horizonte), e as segundas, o projeto "Escuta Diversa", na Universidade de Brasília (UnB).

O surgimento de experiências de extensão e "coletivas" LGBTs coincide com algumas mudanças na sociedade brasileira, dentre elas, a consolidação das redes sociais na década de 2010, a ampliação das políticas de acesso à universidade, a expansão de atividades de extensão popular nas universidades e o fortalecimento dos movimentos sociais identitários (lutas feministas, movimento negro, comunidade LGBTI+, etc.). Esses processos alteraram o movimento estudantil suas demandas e formas de organização interna, com a inclusão de pautas como ações contra o racismo e a LGBTfobia.

Nesse contexto, a presente reflexão nasce com particularidades importantes: todas as autoras estiveram envolvidas nas atividades descritas, estão identificadas com essas mudanças na universidade e estão empenhadas na construção de uma memória do projeto em cenários que tendem a negar essas experiências.

A propósito, consideramos que a memória, seu desaparecimento ou sua permanência, transformada em uso para o presente, não se estabelece apenas a partir de comportamentos psicofisiológicos (Rossi, 2010). Há por detrás daquilo que está disponível para ser lembrado, investimentos das relações de poder e vestígios das disputas sociais. Toda narrativa sobre o passado é situada, o que nos levaria afirmar, talvez, a imprestabilidade de sua produção. Porém, o paradoxo da ativação de uma narrativa, ainda que situada, está no fato de "com as forças exclusivas do presente não se constrói o futuro" (Grossi, 2005).

Em seu conjunto, os poucos estudos disponíveis sobre a extensão LGBT apontam para a necessidade de utilizar o acúmulo do debate sobre a LGBTfobia nas escolas para compreender o espaço universitário e estão centrados nas narrativas das participantes. Do ponto de vista metodológico,- muito embora este texto trate de uma experiência compartilhada e pessoal de várias de nós- utilizamos diferentes estratégias na sua reconstrução: a) análise documental dos programas da disciplina, 
dos projetos de pesquisa e dos espaços virtuais construídos pela coletiva; b) uso da memória compartilhada do grupo, mediante a escrita de várias integrantes e depois a validação coletiva da versão final; c) entrevistas ou consultas a algumas das autoras que são citadas nos textos ${ }^{5}$ d) busca de informações em sítios de internet de órgãos governamnetais, instituições públicas, etc.

O texto, portanto, se insere num duplo movimento. Primeiro, para constituição de uma memória coletiva dissidente. Esse processo é uma estratégia válida para que possamos nos contrapor aos processos de exclusão institucional de formação da memória, onde um modelo de gestão nos considera, quase sempre, invisíveis ou ameaçadoras, e ao processo de dispersão mediática da memória, em que nossas experiências são apresentadas, porém, sob o efeito da imediatidade, do excesso e dispersão da informação, sem peso institucional, não constituem uma narrativa ${ }^{6}$. Segundo, para compartilhar essas experiências com outras de nós e pessoas interessadas na construção de uma sociedade mais livre e igualitária, onde corpos e performances dissidentes possam existir sem serem submetidos às diversas formas de violência do poder heterocisnormativo.

Entretanto, este texto é um exercício insuficiente por diversas razões. A primeira, diz respeito ao tipo de estratégias discursivas e políticas que adotamos em nossas práticas cotidianas, influenciadas pela oralidade e pela arte. Este texto, em sua linguagem formal e em seu esforço descritivo, apenas serve de complemento dessa perspectiva. A segunda, diz respeito ao fato de que para nós o conceito de experiência situada é uma perspectiva central de nossa visão de mundo. Isso implica dizer que uma parte importante de nossa memória parte de como a historicidade do mundo, das relações de poder e de nossas resistências, são permanências discursivas em nossos corpos. Diante disso, organizamos o livro Corpolítica-contranormatividades periféricas (2019) com narrativas sobre as experiências de algumas das integrantes que serão citadas ao longo do texto.

Consideramos relevante propor a presente narrativa acadêmica por ela ser capaz de se constituir em relato inicial sobre diversas dinâmicas em que estivemos envolvidas, de ser comunicada em outros espaços e inter-relacionada a relatos posteriores de outras participantes.

5. Agradecemos especialmente ao João Victor Martins, que concedeu um relato sobre a construção do projeto disciplinar da matéria “Diversidade Sexual, Efetividade de Direitos e Acesso à Justiça” (2015, UnB).

6. Paul Virilio anuncia esse fenômeno em diversos dos seus textos (Virilio, 1999; 2015). 


\section{A Extensão Universitária e a heterocisnormatividade}

Espaços acadêmicos são vividos e descritos como lugares marcados pela discriminação. Apesar de nosso foco central ser a reflexão sobre a experiência de extensão de uma coletiva LGBTI+, há múltiplas dimensões que constroem o cenário no qual as distintas formas de exclusão são vivenciadas de forma intersecional? . Nossa coletiva tematizou, além da heterocisnormatividade, as exclusões relativas ao racismo, ao machismo e à vivência em espaços da periferia, o que é uma novidade no campo de disputas em que nos situamos.

No Brasil, a extensão universitária é consagrada, inclusive, pela Constituição que estabelece a indissociabilidade entre ensino, pesquisa e extensão (art. 207). Na perspectiva da "educação popular", a extensão é uma estratégia de comunicação para estreitar o relacionamento da universidade com a sociedade, superando o conteúdo de uma educação bancária, domesticadora e alienante (Freire, 1985). A educadora deveria debater com o público protagonista o liame entre os saberes comunitários e os conteúdos acadêmicos, para que sejam possíveis múltiplas interações entre os saberes da universidade e a experiência social de cada indivíduo (Freire, 1996).

Entretanto, a proposta de pensar em um diálogo entre o dentro (a universidade) e o fora (a sociedade) esbarra em algumas questões importantes, especialmente quanto ao modo como, em sua estrutura, a universidade exclui formas não "normalizadas" de conhecimento ou conhecimentos produzidos por protagonistas não "normalizadas". A propósito, Michel Foucault valeu-se da categoria de normalização para indicar a tentativa de definir e construir os sujeitos do conhecimento a partir do código normal versus anormal, e de técnicas de sujeição que incluem um vasto sistema de sanções não necessariamente jurídicas, mas que pretendem moldar as possibilidades de liberdade de criação das subjetividades ou produzir e modular o desvio (Foucault, 1985). As perspectivas críticas de intelectuais do campo feminista, antirracista e LGBT denunciam as relações entre saber e poder nas práticas acadêmicas, responsáveis por excluir e demarcar diferenças como indesejáveis e subalternas. Em sociedades periféricas, um dos elementos estruturantes é a branquidade que, como sistema de poder racializado e generificado, produz exclusões de sujeitos e de saberes dissidentes ao ideal de cultura europeia, branca, masculina, heterocisnormativa, e que não sejam funcionais para a reprodução das relações de poder hegemônicas.

Na Universidade, refletem-se as dimensões sociais, mas também estabelecem-se dinâmicas institucionais, nas quais os "campos de conhecimento" apresentam-se com relativa autonomia em relação à sociedade, ou seja, o espaço institucional

7. Consideramos a interseccionalidade não como sobreposições de discriminações, mas como interações que reconstroem posições específicas de opressão (Piscitelli, 2008: 268). 
autonomiza-se, mas é produzido por, e produz, dimensões estruturais. Possui, portanto, fortes vínculos com o ambiente externo e, ao mesmo tempo, especificidades internas. A violência está na estrutura burocrática e acadêmica, mas também nos "detalhes" das paredes dos edifícios, nas formas de tratamento, nos olhares, nas proibições a ocupar posições de fala ou de gestão etc. Isso não significa que a universidade, como outros espaços institucionais, não seja um espaço de disputas, tensões e possibilidades contra-hegemônicas, mas anuncia novos problemas para as categorias de extensão.

Nesse contexto, as premissas construídas sobre a experiência extensionista do Projeto Corpolítica se situaram num terreno de difícil localização, mesmo dentro do marco da "educação popular", pois não havia uma identificação possível com as formas tradicionais (e, às vezes, aparentemente alternativas) de poder acadêmico e as práticas extensionistas alternativas que silenciavam sobre as experiências dessas sujeitas. A oposição ao caráter normalizador do conhecimento acadêmico, mesmo crítico, foi determinante das opções de atuação e são o foco central das descrições e reflexões que propomos. Esse não lugar ocupado pelo projeto representa a dimensão institucional do não lugar ocupado por suas integrantes no cotidiano escolar, como afirma Jefie Cardoli:

Nos dias de hoje, quando volto o meu olhar para esse não tão longínquo passado, percebo que de fato eu nunca havia pertencido ao território da masculinidade, e toda a sua simbologia e significados pra mim eram vazios. Não é questão de ceder e dizer que eles estavam certos, mas sim de não me ver ou não me sentir contemplada em nenhuma performance de gênero ligada ao que é ser homem. Da mesma forma que eu também não me sinto pertencente ao espaço e território do gênero ligado ao ser mulher. Diante desta fissura que se abriu entre meus pés, de não me reconhecer em nenhuma das performances de gênero preestabelecidas pela sociedade, o existencialismo me transbordou, voltando-me à questões sobre "o que eu sou?" e "que lugar eu ocupo?”. (Cardoli, 2019c: 52)

\section{Corpolítica: um projeto de enfrentamento e negociação com os sistemas tradicionais de poder acadêmico e social}

A Corpolítica surgiu em 2014, nos jardins da Faculdade de Direito, com o encontro de aproximadamente vinte LGBTI+. As estudantes da Faculdade de Direito e um professor começaram a dialogar sobre a importância de um grupo naquele espaço. Ao longo do mês de novembro, o grupo espalhou convocatórias para construir a coletiva. A primeira reunião oficial foi no dia 15 , embaixo do mezanino norte do Instituto 
Central de Ciências (ICC). Essa pequena mudança espacial marcou um paulatino deslocamento da composição com a chegada de integrantes de outros cursos.

A coletiva se tornou projeto de extensão em 2016. O projeto incluiu atividades sobre territorialidade, gênero, sexualidade, raça/etnia, direitos de minorias e identidades de lésbicas, gays, bissexuais, transexuais, travestis e intersexo (LGBTI+), tendo como público-alvo as jovens das periferias do Distrito Federal. As reuniões ocorriam no Campus, nas proximidades do Museu Nacional e em regiões periféricas onde algumas das integrantes vivem. Muitos do momentos de lazer foram próximos ao terminal de ônibus ou do metrô. A escolha desses locais decorreu da percepção de que a procura por liberdade, igualdade e justiça social, e as mudanças políticas e sociais necessárias a sua realização, se fazem em diferentes territorialidades (Bizzotto; Nascimento; Gonçalves, 2014). O pertencimento ao espaço é uma dimensão relevante para as pessoas LGBTI+e, ao mesmo tempo, uma das questões centrais de nossas disputas por direitos. Como explicita Jefie Cardoli em uma de suas narrativas:

Cresci e moro em Samambaia, uma das maiores periferias de Brasília, mas durante a minha infância mantive bastante contato com o Entorno do Distrito Federal (DF), especificamente Águas Lindas de Goiás, onde moram meu avô e meu pai, os quais eu visitava com frequência. E apesar de criança, eu sempre tive um olhar crítico para as coisas que estavam ao meu redor e desde aquela época, de idas e voltas a Águas Lindas, eu observava a precariedade dos serviços públicos daquela cidade. E ainda que de forma ingênua e sem o debate de raça e classe que tenho hoje, eu conseguia perceber a desigualdade entre uma criança do Entorno e eu, criança do DF, como também, naquela época eu já havia reparado que eram os corpos negros que davam cor àquela cidade. (Cardoli, 2019a: 42)

O objetivo do projeto era a promoção de consciência cidadã, tanto das sujeitas envolvidas quanto das coletividades. Preocupava-se com a produção de conteúdos informativos e de vivências sobre direitos humanos para a população LGBTI. Ao ser construído com o empoderamento dessas sujeitas excluídas e por seu protagonismo em todas as atividades, foi se transformando ao longo do tempo. Além da vivência territorializada, havia a interação por meio do compartilhamento das produções nas redes sociais ${ }^{8}$.

Do ponto de vista teórico, o projeto dialogou com as propostas de Paulo Freire, Guacira Lopes Louro e as perpectivas Queer, reconstruindo-as desde a prática extensionista. 
Somos "dissidentes", pois a sociedade lê nossos corpos como "estranhos" perante os saberes normativos, como os saberes da Medicina, a Psicologia, o Direito e a Educação. Muitas de nós somos bichas pretas, não binárias, afeminadas, travestis, transexuais, sapatonas, bissexuais, lésbicas negras. Propomos compreender e vivenciar essas diferenças como um potencial para fissurar esses dispositivos discursivos que tentam ditar normas para a existência, sejam elas as formas de sexualidade ou de gênero (Louro, 2001).

Na elaboração do projeto de extensão, propusemos metodologias identificadas com a atuação da coletiva: as rodas de conversa, as histórias de vida, a escuta sensível e oficinas participativas.

Nas “Rodas de Conversa" o aprendizado acontece em interação dialógica a partir da escuta atenciosa dos relatos da outra, o que provoca uma aproximação das participantes, reduz a sensação de solidão, e fortalece a união, por meio das trocas de vivências (Afonso; Abade, 2008). Elas visam, principalmente, fomentar discussões e interesses acerca da conjuntura político jurídica do país, com reflexões pautadas pela interseccionalidade entre os temas da raça, da sexualidade, da identidade de gênero e do território, para aprimorar e potencializar nas participantes o empoderamento e emancipação corporal e psicológica capazes de auxiliar no enfrentamento das discriminações cotidianas.

As "Histórias de Vida" proporcionam às sujeitas narrarem suas próprias histórias, ressignificando os atos de violência e preconceito, os quais já presenciaram ou do qual foram vítimas. As histórias impulsionam a identificação entre as sujeitas participantes que se reconhecem nas situações relatadas (Silva; Barros; Nogueira; Barros, 2007). Desse modo, o lugar do saber é daquelas que falam de suas vivências. Ao relatarem suas histórias, as sujeitas ganham espaço de fala ${ }^{9}$ e passam a se ver

9. Entede-se "Espaço de Fala" como o processo no qual sujeitas/os em situação de sub-representação podem subverter a lógica das instituições que os silenciam e impedem que suas narrativas políticas sejam ouvidas e/ou legitimadas, e entende-se também como processo de tomada de consciência sobre o seu espaço no mundo. Spivak (2010) problematiza em seu texto como as sujeitas/os subalternos encontram dificuldades em legitimar os seus conhecimentos. Djamila Ribeiro, ao falar sobre os embates identitários no movimento feminista, demonstra a importância de constituir espaços para as histórias subalternizadas: "Nesse diálogo, que também se refere a protagonismo, capacidade de escuta e lugar de fala, façamo-nos as perguntas: Que histórias não são contadas? Quem, no Brasil e no mundo, são as pioneiras na autoria de projetos e na condução de experiências em nome da igualdade e da liberdade? De quem é a voz que foi reprimida para que a história única do feminismo virasse verdade? Na partilha desigual do nome e de como, os direitos autorais ficam com as Mulheres Negras, as grandes pioneiras na autoria de práticas feministas, desde antes da travessia do Atlântico. Como herdeiras desse patrimônio ancestral, temos em mãos o compromisso de conferir visibilidade às histórias de glória e criatividade que carregamos. Esse turning point nas nossas narrativas relaciona-se com a principal pauta do feminismo negro: o ato de restituir humanidades negadas (Ribeiro, 2017: 22). (fechar as aspas) 
como possuidoras de suas próprias narrativas, com capacidade para transformá-las. Como narra Jefie Cardoli:

\begin{abstract}
Nunca me senti uma pessoa esteticamente bonita, talvez eu de fato não seja, nunca me vi pertencente a nenhum padrão estético, seja ele o hegemônico: branco, seja ele o que demarca a beleza negra (também não me vejo representada pela estética do tombamento). Penso eu, que ocupo um não-lugar no mundo da estética, assim como ocupo um não-lugar dentro dos limbos identitários, um não-lugar na sociedade, um limbo que serve para caber os corpos esquecidos, os corpos subalternos, corpos abjetos, fora do espectro imaginário do desejo e da afetividade, corpos que estão em constante dissidência à normatividade compulsória, aqueles corpos que não representam nada além deles mesmos... e há tempos é isso que eu sinto, um auto-pertencimento e uma auto-representação, e por isso escrevo tanto e falo tanto, porque somente eu me dou voz. Aconsequência disso talvez seja a constante solidão que muitas como eu vivenciam, mas nunca é alto o preço a pagar pelo privilégio de pertencer a si mesmo. (Cardoli, 2O19b 49)
\end{abstract}

Os relatos sofrem processos de ressignificação, o que permite às participantes a compreensão do contexto das interlocutoras, elaborado por uma articulação entre o social e o psicológico. Nesse movimento discursivo interpretativo entre locutoras e receptoras, cria-se um campo de possibilidades para a resistência. (Silva et al, 2007). Como expressou Taya Carneiro:

Dai eu poderia falar que isso aqui é uma disputa de discursos de poder nos termos de Foucault, ou eu poderia dizer que é uma luta de classes nos termos de Marx. Mas no momento eu to preferindo dizer que isso aqui é tiro, porrada e bomba nos termos de Valesca Popozuda. E por fim, eu queria mandar uma mensagem pros "politicamente incorreto” que acham que militância é modinha: Se liga ai que tu vai rodar, e a gente não vai nem precisar sujar as mãos que nem vocês. (Carneiro, 2019: 82)

A “Escuta Sensível” permite a compreensão da outra, ao auxiliar uma prática de convivência respeitosa, transfigurando as histórias e relatos de cada uma em aprendizados. A partir do relato de vivências de cada pessoa, unido a conceitos e proposições trazidos pelo saber popular e urbano, pela comunidade acadêmica e, também, pela atuação em movimentos sociais, cada pessoa instiga a outra a falar e a escutar os posicionamentos divergentes (Barbier, 2004).

As "Oficinas Participativas" permitem a produção do conhecimento, de feitio coletivo, pois partem do princípio de que todos têm a aprender e a ensinar. Por ser uma metodologia participativa, as participantes estão envolvidas como sujeitas e agentes, bem como aprendem a realizar um trabalho interdisciplinar, de forma 
integradora (Enricone; Grillo, 2005). Sobre isso, Mariah Gama reflete a respeito de um texto criado em uma das oficinas:

Esse texto nasce da minha sobrevivência a dores que imaginei não conseguir suportar. Dores emocionais e afetivas que me fizeram crer profundamente que a infelicidade me perseguiria por toda a vida, porque eu estava amorosamente perturbada, e eu acreditava que isso, de alguma forma, definiria todo o resto. (Gama, 2019: 60)

Portanto, as metodologias utilizadas demonstram o diálogo com a educação popular e a constituição de um espaço para vozes plurais, dissidentes e silenciadas na extensão universitária.

Nós nos transformamos em nossas trajetórias e a Corpolítica vivenciou mudanças no seu desenho inicial, inclusive pela interação com novas pessoas que entravam a cada semestre no projeto. Cada semestre ficou marcado pelas experiências consolidadas e intensificadas pelo grupo que passou a integrar as atividades. Informalmente, a coletiva chama essas mudanças, no formato do grupo, de "temporadas", o que reflete as disputas por representação e o uso de referências da cultura de massa.

A primeira temporada do nosso projeto já institucionalizado como extensão iniciou no primeiro semestre de 2016. Fizemos rodas de conversa e oficinas sobre Direitos Humanos no espaço “Jovem de Expressão" ${ }^{\circ 0}$ em Ceilândia, cidade periférica do Distrito federal. Os temas centrais nesse semestre foram racismo, afeto entre mulheres, identidades e religiões de matriz africana. Na segunda temporada, segundo semestre de 2016, atuamos no espaço Casa Frida em São Sebastião, outra cidade periférica. Nos propusemos a fazer atividades com um diálogo mais constante e contínuo com a comunidade em que estávamos inseridas. Por este motivo, além das rodas de conversa, nos organizamos em grupos de trabalho que conduziam atividades artísticas, tais como, lambe-lambe (colagens de cartazes), zines, desenhos, ensaios fotográficos, poesia, produção cultural etc. Realizamos oficinas em escolas públicas, o que nos permitiu atuar junto às profissionais da educação da rede pública. Na terceira temporada, primeiro semestre de 2017, atuamos no espaço da ocupação

10. O Espaço Jovem de Expressão "trabalha para evidenciar a inteligência advinda dos movimentos culturais da juventude e suas formas de convivências e transformações no mundo contemporâneo. As expressões culturais e de identidades são fundamentais para entender o papel da juventude nas transformações de consumo, produção e de novos arranjos produtivos. Dessa forma, nosso papel é criar espaços, facilitar a colaboração e apoiar a geração de autonomia entre os jovens.” Disponível em: http:// jovemdeexpressao.com.br/quem-somos/ 
do Mercado Sul ${ }^{11}$, em Taguatinga, integrando as atividades desse projeto. Na quarta temporada, segundo semestre de 2017 , decidimos realizar atividades conforme as demandas das comunidades. Optamos por um semestre de formação interna, na qual estudamos nossos próprios métodos e referenciais teóricos.

Durante todas as temporadas, fizemos articulação com o governo do Estado e organizações de caráter internacional para incentivarmos a criação de políticas públicas voltadas para a comunidade LGBTI, e realizamos atividades para debater a cidadania LGBTI com a sociedade. Essas atividades tiveram como marca o diálogo, especialmente, com o movimento LGBT e instituições internacionais, a utilização de estratégias ligadas à cultura, em novos espaços sociais criados ou agenciados pela coletiva, e à mídia, tais como campanhas, entrevistas, debates etc. Destacamos algumas das atividades que ilustram as formas de intervenção da Coletiva.

Colaboramos no projeto “TransFormação" da ONU nos anos de 2017 e 2018. O projeto ofereceu formação para pessoas trans sobre seus Direitos e sobre instrumentos jurídicos e políticas públicas específicas. Participamos do "Mutirão de Casamentos LGBT's simbólicos (2015), ato criado em resposta ao Governo do Distrito Federal que havia prometido a realização de um mutirão de casamentos LGBTI+, mas que, por conta da pressão dos setores conservadores, foi cancelado. A coletiva realizou o ato com casais de sexos diversos, de múltiplas cores, poliamorosos etc. em sinal de protesto contra o fundamentalismo que se opõem às famílias LGBTI+. No mesmo contexto, atuou na "Primeira Parada LGBT da Universidade de Brasília" (2015) e na " 1 a Semana de Visibilidade Transexual de Brasília" (2017) 12.

Criamos diversas atividades culturais que receberam o nome de Sarau LGBT's. Em parceria com a Casa Frida em São Sebastião (DF), organizamos o sarau "Delação, Arte, Linguagem, Afeto e Política" (2016). Houve atividades musicais, poesias, performances e produções imagéticas, com objetivo de refletir sobre o fazer político com linguagens tais que consigam potencializar temáticas diversas: desde o Direito à Cidade até o Sistema Prisional. No ano seguinte, o"Sarau LGBT: Arte é nossa resistência" no Mercado Sul em Taguatinga (2017). O projeto surgiu como resposta aos ataques de censura à arte LGBTI+ e à patologização dos corpos LGBTI+, pois nas semanas anteriores à realização do Sarau foi conferida liminar judicial a fim de permitir o tratamento de homossexualidade como doença.

11. O Mercado Sul é uma "Ocupação Cultural de artes, cultura livre, capoeira, cinema, economia solidária, saúde, educação e cultura popular” fica localizado em Taguatinga, no Distrito Federal. Mais informações podem ser acessadas em: "http://www.mercadosul.org/" e "https://www.facebook.com/ mercadosulvive/".

12. Em 2017, fomos premiadas pelo "Programa Bolsa Ativismo" do "Nossas - laboratório de ativismo" que buscava reduzir a taxa de homicídios em países com altos índices de letalidade. 
Enquanto projeto, também participamos de diversas ações na Orrganização das Nações Unidas (ONU), sobretudo em ações partes da campanha "Livres e Iguais". Dentre elas, protagonizamos o vídeo "UN Free \& Equal: Why We Fight", representando o ativismo LGBTI+ brasileiro, e ainda diversos webdocumentários ("Nosso presente é o amor", "Iana: Uma história emocionante de aceitação" e "Por que eu luto-Rebecca"). Estivemos na roda de conversa "Visibilidade Lésbica: que visibilidade nós queremos?" e na campanha da Semana de Visibilidade Bissexual. Para além destas ações com a institiuição, estivemos no programa de televisão "Conexão Futura" que tratou sobre evasão de jovens LGBTI+ das escolas. E, ainda, nossas integrantes escreveram e colaboraram no livro "Nós, Trans - Escrevivências de Resistência”, uma iniciativa da editora Litera Trans.

Além dessas atividades, a Corpolítica desenvolveu duas estratégias para vincular a extensão ao ensino e à pesquisa.

Inicialmente, em parceria com o coordenador do projeto, debatemos a criação de disciplinas sobre a temática LGBTI+ na Faculdade de Direito (FD-UnB). Elas se constituíram em espaços acadêmicos habitados por corpos e performances identitárias negadas pela normalização heterocisnormativa.

Em 2015, a disciplina foi ofertada pelo coordenador, sob o título "Diversidade Sexual, Efetividade de Direitos e Acesso à Justiça”, com quinze estudantes. Nessa ocasião, a Corpolítica começava a se efetivar como uma coletiva e as alunas tinham a expectativa de formar um grupo de pesquisa ${ }^{13}$. A metodologia proposta incluía, com enfoque interdisciplinar, além de aulas sobre temas LGBT, a construção de atividades coletivas de pesquisa. Dois temas serviram como eixo das atividades: "Inserção de pessoas trans na universidade" e "Casamentos homoafetivos".

No primeiro semestre de 2017, a disciplina "Direitos LGBT" buscou "valorizar as experiências acadêmicas que ocorrem fora dos métodos de ensino tradicionais, sobretudo experiências em extensão universitária no intuito de visibilizar diferentes formas de produção de conhecimento através da imersão em contextos de minorias políticas e sociais" ${ }^{14}$. Ademais, valorizou a formação em metodologia de pesquisa sobre temáticas LGBTI $+{ }^{15} \mathrm{~A}$ disciplina foi coordenada pela Prof a ${ }^{\text {. Denise Mantovani }}$ (Instituto de Ciência Política - IPOL/UnB), com a colaboração do Prof. Evandro

13. Parte dessa proposta foi, em parte, realizada pela Resistir, outro projeto de extensão surgido em 2016 na Faculdade de Direito que, inicialmente, era integrada por estudantes que participaram da disciplina. 14. Plano da disciplina "Direitos LGBTI+" ofertada no $1^{\mathrm{O}}$ semestre de 2017 na Universidade de Brasília. 15. Plano da disciplina “Direitos LGBTI+” ofertada no $1^{\mathrm{O}}$ semestre de 2017 na Universidade de Brasília. 
Piza Duarte (Faculdade de Direito - FD/UnB), com a participação de especialistas em seminários e com um público de diversos cursos ${ }^{16}$.

No segundo semestre de 2017, a disciplina "Direitos LGBT" voltou-se, novamente, para a reflexão das práticas de extensão e pesquisa desde uma perspectiva situada. A escolha acompanhava a preocupação de refletir sobre nossas práticas. As aulas trataram sobre as metodologias disponíveis para a extensão, os conflitos e as disputas feitas por grupos sociais discriminados no sistema educacional ${ }^{17}$.

Em comum, as estratégias adotadas para manter o caráter dialógico ${ }^{18}$ das disciplinas foram:

a) consulta por meio das redes sociais sobre a inclusão de conteúdos, temas, metodologias nos programas; b) diálogo sobre a construção do programa, especialmente, sobre quais seriam as habilidades a serem desenvolvidas e os objetivos a serem alcançados; c) uso de estratégias como seminários protagonizados pelas estudantes e por convidadas, além de debate aberto em formato de roda para valorização da horizontalidade, do diálogo e, especialmente da experiência pessoal das pessoas envolvidas na construção do ambiente de sala de aula; d) uso de estratégias de aprendizagem que mantivessem em perspectiva a relação dinâmica entre teoria e prática, valorizando os saberes práticos como uma dimensão relevante da formação intelectual, intentando questionar a divisão social do trabalho de gênero, raça e classe; e) mediação com os conteúdos que "circulavam" no ambiente extraclasse, especialmente com as situações que provocavam estresse às estudantes LGBT, como

16. As aulas de metodologia de pesquisa tiveram participação de Fernanda Martinelli (Faculdade de Comunicação - FAC/UnB) e Gabriela Rondon (Instituto de Bioética - ANIS); As aulas de Teoria Queer no Brasil de Tatiana Lionço e Felipe Areda (Centro de Estudos Avançados Multidisciplinares - CEAM/UnB); As aulas sobre Afrolatinidades de Marcos Queiroz Lustosa, Marcelo Caetano e Gabriela Barreto de Sá (MARÉ - Núcleo de Estudos em Cultura Jurídica e Atlântico Negro); A aula sobre Extensão Universitária de Renata Costa (Faculdade de Direito - FD/UnB); As aulas sobre lesbianidade de Val Peixoto (Departamento de Serviço Social - UnB); e por fim, as oficinas de audiovisual contaram com a participação de Clayton Nobre e Gabriela Garcia, do coletivo de comunicação Mídia Ninja (mais informações sobre o coletivo em: http://midianinja.org/).

17. Plano da disciplina “Direitos LGBTI+" ofertada no $2^{\circ}$ semestre de 2017 na Universidade de Brasília.

18. Tomamos de Bakhtin a expressão dialógica em oposição a falsa pretensão de que a comunicação e o processo de aprendizado possam se realizar em uma única direção e que produzam, portanto, um único sentido, governado pelo Professor. Além disso, acreditamos que o espaço de sala de aula deve ser polifônico, ou seja, integrado por múltiplas vozes, sem que haja a pretensão de redução de todos a uma única consciência. Embora os dois conceitos-chave na obra de Bakhtin sejam muitas vezes utilizados como sinónimos: "O dialogismo define as relações linguageiras, as práticas discursivas e, mais do que isso, a visão de mundo de Bakhtin. Já a polifonia se refere à multiplicidade de vozes em um texto, seja ele literário ou não. A polifonia pressupõe uma multiplicidade de mundos, ou seja, vários sistemas de referência, vozes plenivalentes e pontos de vista ideológicos acerca do mundo" (Marcuzzo, 2008: 91). 
campanhas LGBTfóbicas, atos de discriminação sofridos no ambiente escolar, relatos sobre o cotidiano; f) respeito à diferença, sem transformá-la em algo exótico ou apenas tolerável no espaço da classe; g) preocupação com a representatividade na execução de todas as atividades, incentivando-se a participação de interlocutoras de todos os grupos discriminados; h) valorização dos espaços cotidianos, como intervalos e pré-classe, como momentos de conhecimento e de escuta; i) relativização do lugar do professor como detentor do conhecimento pelo diálogo com outras especialistas e com a produção do conhecimento desde o protagonismo e o interesse das estudantes; j) aprendizado voltado para o empoderamento das estudantes no ambiente universitário, especialmente para a pesquisa e a escrita acadêmica situada.

Quanto à iniciação científica sobre temas LGBT, constatamos que muitas das estudantes não eram acolhidas em seus interesses de pesquisa, que as redes acadêmicas tendiam a negar a nossa presença sob o pretexto de que os interesses de pesquisa não eram compatíveis com as linhas em desenvolvimento pelas orientadoras ou de que elas não tinham "formação sobre o tema". Nesse contexto, desenvolvemos estratégias de sensibilização de orientadoras nas respectivas áreas de interesse das estudantes, incentivando o diálogo com as professoras que demonstrassem abertura, e alcançamos realizar diversas iniciações científicas, publicando trabalhos nos anais do “220 e $23^{\circ}$ Congressos de Iniciação Científica da UnB" ${ }_{19}^{20}(2016 / 2017)$.

Além das iniciativas de formação individual, houve a organização em parceria com o Projeto Reexistir, do "10 Seminário de Ensino, Pesquisa e Extensão LGBTI+" (2017), atividade acadêmica de apoio mútuo entre Coletivas LGBTI+. Ele contou com dois grupos de trabalho ("Coletivas LGBTI+, Extensão e Pesquisa na Universidade" “Pesquisas em Gênero e Sexualidades, LGBTI+ e Direitos Humanos”), participação de 145 pessoas e apresentação de 25 resumos de textos ${ }^{21} 22$.

Enfim, antes e durante a nossa atuação como projeto de extensão, nos estruturamos também como uma coletiva e empreendemos ações que fizeram dialogar

19. Anais do evento disponível em:

http://conferencias.unb.br/index.php/iniciacaocientifica/23cicunb14df/schedConf/presentations

20. Anais do evento disponível em:

https://drive.google.com/file/d/oBwQYroqAt92oRGpSRGZ5MGhtMoU/view.

21. As inscrições nas atividades foram feitas por meio do site "https://www.even3.com.br/seminariolgbti" e a divulgação no facebook consta no link https://www.facebook.com/events/1602524249808812/.

22. Nas áreas de conhecimento das autoras, há predominância de trabalhos escritos por estudantes de Direito (23\%), Psicologia (23\%) e Letras (9\%). A seguir, de forma pulverizada, com 6\% (Saúde Coletiva, Ciência da Computação) e com 3\% (Gestão de Políticas Públicas, Comunicação, Farmácia, História, Filosofia, Ciências Sociais), sendo que 12\% não informou o curso. Dados obtidos na plataforma do seminário (https://www.even3.com.br/seminariolgbti). 
ensino, pesquisa e extensão. A nossa proposta de organização intitulada "coletiva" tem a ver como pensamos, considerando as vivências e as experiências de todas as pessoas do grupo. Portanto "coletiva" assume o significado de tomar decisões de forma horizontal e, simultaneamente, compreender que cada uma de nós sofre opressões e tem potencial para ser opressora. A ideia de coletiva nos fez dividir não somente as tarefas, mas também as nossas rotinas, recursos, ideias, estéticas etc.

\section{Extensão LGBTI+? Reconhecendo as "estrangeiras de dentro" e as "guerrilhas estético-políticas" nas experiências da Corpolítica}

Há inúmeros desafios e possibilidades em refletir sobre essas experiências. A seguir, sugerimos algumas.

Patrícia Collins (2016), considerou as potencialidades de compreensão da realidade por parte das mulheres negras, propondo a perspectiva de que opressões interseccionais de gênero e raça implicam em experiências capazes de construir novas agências, inclusive, estratégias de escritas. Para a autora, "as mulheres afro-americanas participaram dos segredos mais íntimos da sociedade branca". Ao mesmo tempo, "essas mulheres viram as elites brancas, tanto as de fato como as aspirantes, a partir de perspectivas que não eram evidentes a seus esposos negros ou aos grupos dominantes". O termo outsider within, ou "estrangeiras/forasteiras de dentro" indicaria esse "status" que "tem proporcionado às mulheres afro-americanas um ponto de vista especial quanto ao self, à família e à sociedade", o que seria comprovado pela emergente literatura feminista negra.

Eve Sedgwick (2007) propôs o termo "Epistemologia do Armário" para, desde uma experiência situada, compreender as relações entre a dicotomia público/privado e a construção da regra heteronormativa na vida de pessoas gays. A autora demonstrou como a expressão "sair do armário" fazia sentido porque havia um armário construído pela pressuposição da heteronormatividade. Se creio que um corpo deve ser heteronormativo, "quem não é" deve sair para algum lugar fora desse espaço. Logo, quem estava no armário ora era culpada por não ter saído ora por ter saído ou ter saído na hora errada. A ideia do armário (e de que as gays entram ou saem do armário) pode se tornar também uma armadilha.

Judith Butler (2003), por sua vez, argumenta que a identidade de gênero é performativamente construída, através de expressões de gênero. O corpo torna-se sexuado a partir dos discursos sobre a sexualidade. O conceito de "sexo natural" integra um complexo de poder que atribui significados aos corpos, a suas funções biológicas e 
suas afetividades. A "matriz heterossexual" representa o modelo epistemológico de inteligibilidade dos gêneros que caracteriza os sexos "verdadeiros" (e seus desejos verdadeiros) não somente por aspectos biológicos do corpo, como também sob características de performances de gênero e desejo sexual.

Considerando essas três perspectivas, a Corpolítica se caracterizou pela interseccionalidade (raça, classe, gênero e sexualidades) das opressões sofridas por suas integrantes e por ser um espaço habitado por corpos dissidentes das performances heterocisnormativas. Os relatos das estudantes bissexuais, mulheres e homens trans, não binárias, héteros e gays "afeminadas" evidenciam como não pode haver uma única "epistemologia do armário", pois são vivências comuns, mas distintas em relação às inúmeras performances. Meninos afeminados bissexuais, por exemplo, são, desde muito cedo, tirados do armário, pois publicamente já recebem estereótipos negativos. Mulheres negras lésbicas têm o lugar da feminilidade questionado por conta da associação entre feminilidade e branquidade.

Ademais, no âmbito das disputas internas para nomearmos quem são GLS, LGBT, LGBTI, LGBTQ, ALGBTQI, está a certeza cotidiana que nossas epistemologias necessitam ser escritas no plural. Somos todos os dias interpelados a aprender novas palavras para falar sobre algo que já estava sendo falado, apenas parcialmente. Nesse contexto, os movimentos sociais LGBTs têm sido capazes de reconhecer os limites internos de seu discurso político. Todo dia há algo novo para perceber, no âmbito das práticas de ensino e aprendizagem. A verdade não é uma posse tranquila e segura de nós mesmos, mas uma libélula descrevendo novos caminhos até ser fisgada pela língua afiada de um sapo.

Portanto, muito embora nos situemos no espaço de disputas por construção de processos de compreensão/ação desde uma perspectiva situada, temos em conta que nossa radicalidade em relação ao local da performance da sexualidade e do gênero nos propõe o desafio de que novas experiências de si (de modo individual e coletivo) trazem novas potencialidades, tanto em relação aos locais já conhecidos da opressão e da agência, quanto em relação a novas opressões e agências.

A Extensão LGBT popular é esse lugar plural, em trânsito e em contradição.

Plural, pois nenhuma perspectiva cega ou subalternizante (do gênero, da sexualidade e da raça), ou "gay branca" (internamente hegemônica e cega às dimensões trans, lésbicas, não binárias e racializadas da sexualidade) pode conferir sentido a todas às experiências vividas diante da "matriz heterossexual" e porque essa matriz esta configurada de modo diverso em relação às dimensões interseccionais. Em trânsito, pois muitos dos corpos experimentam, nos espaços de convivência LGBT, processos pessoais de transição e disputas individuais e coletivas por reconhecimento. Em contradição, pois há uma oposição cotidiana com as marcas dessa matriz na 
própria estrutura subjetiva, nas relações familiares e sociais. A possibilidade de viver e falar dessa contradição é o primeiro ganho da extensão.

Ao mesmo tempo, nossas práticas indicam a completa precariedade dos conhecimentos críticos (e ou do acesso a eles) para nossas práticas cotidianas e estratégias políticas. A extensão LGBT traz, ainda, a necessidade de valorização do afeto. A prática do acolhimento é imprescindível para a vida de subjetividades atacadas apenas por existirem, uma forma de ressignificar o desprezo social que é imposto a essas subjetividades. A escolha pelas metodologias que lidam com as emoções, tais como as rodas de conversa, as histórias de vida, a escuta sensível e oficinas participativas, insere-se nesse contexto.

A noção de "armários" e de "matriz heterocisnormativa", por sua vez, propõem refletir sobre a posição de outsider within, ou "estrangeiras/forasteiras de dentro". Numa sociedade em que algumas demandas "gays" são aceitas a partir da absorção restritiva dos direitos de uma parte da comunidade LGBT, especialmente, a parte branca, cisnormativa e burguesa, as perspectivas queer e do feminismo negro recolocam em movimento o debate interno e externo das políticas de reconhecimento. As instituições educacionais são um espaço importante de disputa social, pois são responsáveis pela reprodução da "matriz heterossexual" nos diversos campos da ciência, da política e do poder institucional.

Desde o ponto de vista de performances dissidentes, não há lado de dentro e lado de fora para LGBTs. As opressões podem ser marcadas por dinâmicas institucionais e territorializadas em determinadas práticas. A violência no transporte público não é a mesma dos corredores da universidade, porém, a universidade não pode ser identificada como uma "comunidade universitária", ou outra expressão que indique haver uma totalidade onde as discriminações contra as LGBTs não devam ser explicitamente nomeadas. A heterocisnormatividade está no dentro e fora da universidade. Logo, não se pode aceitar que uma extensão voltada para as LGBTs seja algo necessariamente extramuros.

O muro das discriminações cotidianas está construído dentro de todas as universidades. A heterocisnormatividade compulsória frequenta e se impõe de modo violento em todos os espaços de convivência. Ela está no estranhamento das performances sexuais diversas, na composição do corpo docente, nos rituais masculinos dos espaços das reuniões de departamento, no silenciamento dos problemas que afetam as pessoas LGBTs etc. Não precisamos ir para a rua para encontrar corpos excluídos com os quais temos que dialogar. A extensão LGBTs tem um compromisso com as subjetividades negadas em todos os espaços, inclusive na universidade, onde as performances não heterocisnormativas são "estrangeiras de dentro". Logo, essa relação transforma as narrativas sobre extensão ("sobre ir à periferia", "sobre ir à 
comunidade" etc.). É indispensável redefinir as alianças de intervenção social desde a universidade a partir de um patamar mínimo em que nossa presença seja explícita e conscientemente reconhecida. Uma extensão não pode ser popular se não for capaz de falar sobre heterocisnormatividade compulsória, sobre lesbofobia, sobre transfobia, sobre bifobia etc. É contraditório ir à periferia dialogar sobre dimensões econômicas da exclusão social sem perceber que a heterocisnormatividade compulsória e as diversas formas de discriminação a ela associadas estruturam também a economia, a distribuição de direitos e os espaços que chamamos de periferia.

A compreensão dessa relação dentro/fora também altera o modo sobre como podemos produzir conhecimento. A autoetnografia realizada por várias pessoas de nossa coletiva demonstra a potência da escrita desde as experiências que estão vivas entre nós. Poder narrar a si mesmo parece algo trivial. Entretanto, para quem sempre foi objeto de narrativas construídas pelo poder médico, jurídico e acadêmico, élibertadora a construção de espaços nos quais possam nascer discursos sobre nós mesmas.

A todo momento a Coletiva e o Projeto de Extensão foram interpelados pela noção de interseccionalidade. Porém, se a linguagem também constitui a realidade, o debate acadêmico sobre conceitos não esgota as dimensões políticas, estruturais e cotidianas do uso das palavras. Ensino, extensão e a pesquisa LGBT são mais do que tentativas de isolamento artificial da pluralidade da vida por meio de discursos acadêmicos. Todos os dias convivemos com mulheres LGBT que têm suas vidas construídas desde relações de gênero, com pessoas negras LGBT que têm suas vidas construídas desde relações racistas, com pessoas pobres LGBT que têm suas vidas construídas desde relações de exclusões econômicas etc. Nesse contexto, a academia e as redes sociais trazem um risco para a prática cotidiana. O espaço da universidade por ser fundado, muitas vezes, na enunciação e nos jogos discursivos, incitam a pensar as ações políticas e as trajetórias de vidas como meros jogos de enunciação, em que dizer equivaleria (falsamente) a fazer algo. As redes sociais, por sua vez, promovem o ato singular, com efeito cênico, mas alheio à continuidade das tramas do cotidiano. Por isso, acreditamos que as múltiplas dimensões da vida não precisam ser pensadas apenas sob a ótica da representação ou redistribuição, podendo ser pensadas também desde uma perspectiva da complexidade das disputas sociais e da necessidade de projetos complexos de transformação social. Múltiplas dimensões da vida devem ser capazes de desestabilizar as certezas quanto à nossa posição em relação às formas de reprodução das opressões sociais.

Muito embora haja um esforço para dialogar com o espaço institucional, por meio de atividades conjuntas de ensino, pesquisa e extensão, nossas atividades acadêmicas, não podem converter todas nossas vivências nas dimensões da academia. Isso não significa que as LGBTs não têm muito a ganhar e a oferecer à universidade e à 
sociedade quando pensamos desde as experiências que vivenciamos. Epistemologias LGBTs incitam a criar fora dos binarismos e das perspectivas totalizantes. A presença viva de corpos dissidentes, nos espaços dentro e fora da universidade, incita a pensar em mudanças na matéria mesma das ideias de representação e de redistribuição, e na natureza do espaço que é ocupado por sujeitas de carne e discurso. Isso implica na produção de subjetividades acadêmicas, por meio de redes, dos deslocamentos entre ensino e aprendizado, por meio da dispersão do local da verdade acadêmica. Experiências LGBTs sugerem a redefinição de fronteiras, vão muito além da ocupação de territórios com suas lógicas heterocisnormativas e excludentes.

Ao mesmo tempo, o ensino, a pesquisa e a extensão LGBTs, agenciados por nossas experiências, foram marcados pela frágil posição que ocupamos nas relações de poder acadêmico. Nossas ações provocaram efeitos políticos nos lugares em que não podiam garantir a construção de espaços institucionais (como políticas públicas), foi o caso das atuações "com casamentos simbólicos". Ao mesmo tempo, houve disputas institucionais, como a participação em campanhas da ONU. E, especialmente, atividades culturais como a realização dos "saraus", a participação em rodas de conversa, a produção artística desenvolvida por várias das integrantes. O lugar marginal de nossa produção e a impossibilidade de, efetivamente, ocupar as posições hegemônicas e, portanto, ter de recomeçar em um novo espaço, sugere o termo "guerrilha".

Attina (1998), ao tentar conceituar um termo que, de fato, nasce da prática social sugere que "a Guerrilha é um tipo de combate caracterizado pelo choque entre formações irregulares de combatentes e um exército regular", sendo que "os objetivos por ela perseguidos são mais políticos que militares". E, que ela seria "típica dos Estados nos quais existem profundas injustiças sociais e onde a população está disposta a lutar por uma mudança." Por fim, como tática militar ela "confia muito na improvisação e nas possibilidades de aproveitar a ocasião favorável."

A aproximação do ponto de vista apenas metafórico (e não propriamente real, pois a Coletiva não transita por respostas ligadas à prática militar) é possível. Primeiro porque lidamos com um cenário no qual a matriz heterocisnormativa é hegemônica e se impõe a todo momento como prática e discurso. Segundo, porque uma das caracteríticas centrais de atuação da guerrilha é que ela lida com a precariedade de sua posição estratégica diante de uma superioridade evidente. Terceiro, porque essa matriz, como demonstram Butler (2013) e Foucault (1999), desde um conjunto de práticas e discursos, estrutura o modo de produção das subjetividades, ou seja, ela lida com dimensões simbólicas essenciais à reprodução de desigualdades, violências, hierarquização entre sujeitas etc.

Nesse aspecto, o Projeto de Extensão se insere num processo importante do movimento LGBT que pode ser identificado na emergência de novas expressivi- 
dades. Expressividades que não podem ser entendidas apenas pela noção de arte como produto da alta cultura, onde ocorreria o encontro sublime entre a forma e o conteúdo, ou como arte como produto da tradição popular, onde se manifestaria a beleza "ingênua e a força vital dos românticos", ou mesmo a arte engajada ao projeto político, onde uma agenda, um programa, uma missão se manifestariam. As expressividades LGBTs são manifestações da desconstrução do dispositivo da heterocisnormatividade, implicam em usos da precariedade da vida como forma de reviver-se e, especialmente, como novas experimentações da produção da subjetividade (Blanca, 2011; Cuello, 2013). Muitas vezes, elas denunciam o esgotamento do ideal de arte da alta cultura e da cultura popular em seus compromissos com a reprodução social da heterocisnormatividade. Essas são algumas das razões pelas quais as expressividades LGBTs são atacadas como antiarte ou como não merecedoras desse título, e ainda, supostamente, por ofenderem uma moral supostamente dominante.

Todavia, há um compromisso continuo dessas expressividades muito além do caráter negativo da crítica, pois elas representam formas potentes de construção, manifestam o direito a fazer de si um projeto, a reescrever-se, de um cuidado de si que emerge da precariedade. As novas expressividades têm ocupado uma parte considerável dos espaços LGBTs, e podem potencializar também o espaço acadêmico. Pensar o corpo, a pele, o cabelo, os gestos cotidianos como uma reconstrução, parece ser um contraponto necessário às formas de normalização da escrita, das sensibilidades, da carreira acadêmica e, até, das parcerias acadêmicas.

De igual modo, o impacto na política contemporânea dessas estratégias é evidente. Assim, por exemplo, há menos de duas décadas vivíamos sob a ilusão de que o Estado no Brasil era Laico. Aparentemente ninguém era capaz de denunciar como crenças religiosas eram utilizadas para negar direitos a cidadãos e cidadãs. $O$ Estado Laico saiu do armário graças ao movimento LGBT que denunciou os seus limites práticos.

Enfim, os desafios da extensão LGBT são inúmeros, alguns "novos" outros já conhecidos da extensão popular. $\mathrm{O}$ avanço das políticas de ação afirmativa no acesso à graduação coincide com a entrada de novas sujeitas na universidade brasileira. A extensão LGBT é composta em grande parte por pessoas que vêm de grupos sociais vulneráveis economicamente, com dificuldade de acesso ao mercado de trabalho, por sua localização geográfica periférica, sua performance dissidente quanto à identidade de gênero e por ser integrante de grupos racialmente marginalizados. Programas genéricos de estágio ou de bolsas podem reproduzir essas exclusões sociais. Tais exclusões já estão reproduzidas internamente na quase completa ausência de redes de apoio na universidade. Aqui não nos referimos à assistência estudantil, mas a modelos diversos e específicos, tais como programas para jovens 
trans em processo de transição, serviços de atendimento psicossocial para vítimas de violência LGBTfóbica, programas para o combate à LGBTfobia institucional com formação para a comunidade interna (professoras, estudantes e funcionárias). A ausência de redes de apoio de pesquisa, de disciplinas nos mais variados cursos e de novas sensibilidades institucionais é sintoma e causa dessas exclusões que necessitam de variadas formas de intervenção, inclusive políticas de ação afirmativa na pós-graduação e para o ingresso de professoras.

Nesse contexto, as práticas acadêmicas das "estrangeiras de dentro", em suas "guerrilhas estético-políticas", têm sido essenciais para pensar os dilemas do espaço da extensão numa universidade em que as ações afirmativas ampliaram as formas de acesso dos grupos excluídos.

\section{Considerações Finais}

A Corpolítica demonstrou que a extensão carrega uma potência para uma sociabilidade afetiva de desconstrução e reconstrução das formas tradicionais de saber. E ainda, potencializa a democracia ao trazer debates de reconhecimento e respeito aos direitos humanos das camadas mais vulneráveis da população, submetida a múltiplas opressões sociais. Descrevemos, a propósito, atividades relativas ao ensino, à pesquisa e à extensão que indicam a presença de uma pluralidade de tentativas de estar e transformar a universidade e a sociedade.

As práticas da guerrilha estético-política, por exemplo, permitiram empoderar as pessoas, suas linguagens, narrativas e expressões através da arte. As manifestações artísticas fomentadas possibilitaram que pessoas estranhas à coletiva encontrassem um espaço onde suas experiências fossem valorizadas. Houve muitos esforços para criar uma estética própria e subversiva em relação à heterocisnormatividade. Essa estética encontra-se nos usos específicos da linguagem das chamadas dos eventos nas redes sociais ou nas reuniões, sempre marcadas por termos e conceitos criados/ disseminados por nós, além de gírias próprias com significados compartilhados pelas integrantes da Corpolítica.

Jefie Cardoli e Maria Leo Araruna, ao comentarem sua percepção sobre as decisões favoráveis do Supremo Tribunal Federal aos direitos de pessoas trans e travestis, explicitam essa estratégia:

Um olhar para a História e para a Geografia do esquecimento e da abjeção são importantes em momentos de alegria, de excitação e de queima de laudos. A linguagem ancestral típica das prostituídas das esquinas junto às gritarias e algazarras coletivas das militâncias transcentradas comprovaram sua força nesse dia. Por isso, temos calma e 
convicção suficientes em afirmar: 'Não foi o STF, foi a nossa luta'. Foi a nossa memória incansável pelas que já se foram e pelos que foram expulsos; a nossa preocupação em criar novas linguagens, seja 'cis', 'transgênero', 'transmasculino' ou 'transvestigênere'; a nossa fé nos corpos masculinos embocetados e nas feminilidades penianas; foi a gente, sempre tem sido a gente e as guerrilhas cotidianas que travamos e os discursos que criamos. (Duarte, 2019: 63)

O relato sobre todas as dimensões de nossa atuação apenas foi iniciado e permanece em aberto, pois inúmeras são as outras narrativas em nossos corpos e nossas vidas. No mesmo passo, temos em conta a efemeridade e a intensidade de nossas experiências coletivas diante do aprofundamento de nossas trajetórias individuais e de novas necessidades dos contextos em que vivemos. Na atual conjuntura política, nossa existência está ameaçada por uma política que se organiza em torno do extermínio de corpos, de subjetividades dissidentes e das possibilidades alternativas de presente e de futuro.

\section{Referências}

Afonso, Maria Lúcia; Abade, Flávia Lemos (2008). Para reinventar as rodas. Belo Horizonte: RECIMAM.

Attina, Fulvio (1998). Guerrilha. Em Dicionário de Política (pp. 577-581), coordenado por Norberto Bobbio. Brasília: UnB.

Bagagli, Beatriz Pagliarini (2016). Afinando A Noção De “Socialização” E Refutando Algumas Distorções. Revista Transfeminismo. Recuperado de https://transfeminismo.com/afinandoa-nocao-de-socializacao-e-refutando-algumas-distorcoes/

Barbier, René (2004). A pesquisa-ação. Brasília: Líber Livro.

Bizzotto, Luciana; Nascimento, Júlia; Gonçalves, Raquel (2014). O Espaço e o Poder: por uma práxis no planejamento urbano autônomo. Revista Paranaense de Desenvolvimento, 35(126), 131-145.

Blanca, Rosa Maria (2011). Arte a partir de uma perspectiva queer arte desde lo queer. Florianópolis: Universidade Federal de Santa Catarina.

Butler, Judith (2013). Problemas de gênero: feminismo e subversão de identidade. Rio de Janeiro: Civilização Brasileira.

Cardoli, Jefie (2019a). Divisores de Águas. Em Corpolítica - contranormatividades periféricas (pp. 42-43), coordenado por Evandro Piza Duarte. Brasília: Edição do autor. 
Cardoli, Jefie (2019b). O Não-lugar Que Eu Ocupo. Em Corpolítica - contranormatividades periféricas (pp. 49), coordenado por Evandro Piza Duarte. Brasília: Edição do autor.

Cardoli, Jefie (2019c). Um corpo em fuga: dissidência à normatividade compulsória. Em Corpolítica - contranormatividades periféricas (pp. 51-52), coordenado por Evandro Piza Duarte. Brasília: Edição do autor.

Carneiro, Taya (2019). Escurecimentos. Em Corpolítica-contranormatividades periféricas (pp. 82-83), coordenado por Evandro Piza Duarte. Brasília: Edição do autor.

Cassal, Luan Carpes Barros; Zucco, Luciana Patrícia (2010). Diversidade Sexual e Gênero na Escola: Uma Experiência de Extensão no Rio de Janeiro. Extensão em Foco, 5, 15-23.

Collins, Patrícia (2016). Aprendendo com a outsider within: a significação sociológica do pensamento feminista negro. Revista Sociedade e Estado, 31(1), 99-127.

Cuello, Juan Nicolás (2013). Serigrafistas queer (2007-2012): subjetividades deseantes en permanente vibración. Trabalho apresentado em IX Jornadas Nacionales de Investigación en Arte en Argentina, La Plata.

Piza-Duarte, Evandro (org.) (2019). Corpolítica - contranormatividades periféricas. Brasília: Edição do autor.

Enricone, Délcia; Grillo, Marlene (2005). Educação superior: vivências e visão de futuro. Porto Alegre: EDIPUCRS.

Foucault, Michel (1985). Microfisica do Poder. Petrópolis: Vozes.

Foucault, Michel (1999) História da sexualidade: A vontade de saber. Rio de Janeiro: Graal.

Freire, Paulo (1985). Extensão ou Comunicação. Rio de Janeiro: Paz e Terra.

Freire, Paulo (1996). Pedagogia da autonomia: saberes necessários à prática educativa. São Paulo: Paz e Terra.

Gama, Mariah (2019). Um Mergulho em Mim Mesma: a mulheridade e o amor. Em Corpolítica - contranormatividades periféricas (pp. 6o-61), coordenado por Evandro Piza Duarte. Brasília: Edição do autor.

Grossi, Paolo (2005). O ponto e a linha - História do direito e direito positivo na formação do jurista do nosso tempo. Revista Sequência, 51, 31-45.

Lionço, Tatiana; Tavira, Larissa Vasques; Baére, Felipe de; Portela, Raquel de Souza (2016). Escuta Diversa: Análise da implementação de um serviço de acolhimento e de articulação de rede de proteção para a comunidade LGBT da UNB. Trabalho apresentado em \#4 Seminário Internacional de Educação e Sexualidade. \#2 Encontro Internacional de Estudos de Gênero. Fundamentos e Violências: "O que temos feito de nós?”, Vitória: UFES. 
Louro, Guacira Lopes (2001). Teoria Queer: uma política pós-identitária para a educação. Revista Estudos Feministas, 9, 542-546.

Marcuzzo. Patrícia (2008). Diálogo Inconcluso: Os conceitos de dialogismo e polifonia na obra de Mikhail Bakhtin. Cadernos do IL, 36 .

Piscitelli, Adriana (2008). Interseccionalidades, categorias de articulação e experiências de migrantes brasileiras. Sociedade e Cultura, 11(2), 263-274.

Reis, Roberto Alves; Dias, Jacson; Benitez, Gael (2016). A experiência do projeto de extensão Una-se contra a LGBTfobia: ações a favor de uma cultura do respeito à diversidade sexual e de gênero no ambiente universitário. Revista Científica das áreas de História, Letras, Educação e Serviço Social do Centro Universitário de Belo Horizonte, 9(2), 74-82.

Ribeiro, Djamila (2017). O que é lugar de fala? Belo Horizonte: Letramento.

Rossi, Paolo (2010). O Passado, a Memória e o Esquecimento. São Paulo: Unesp.

Sedgwick, Eve Kosofsky (2007). A epistemologia do armário. Cadernos Pagu, 28, 19-54.

Silva, Aline Pacheco; Barros, Carolyne Reis; Nogueira, Maria Luisa Magalhães; Barros, Vanessa Andrade (2007). Conte-me sua história: reflexões sobre o método de História de Vida. Mosaico - estudos em psicologia, 1(1), 29-30.

Spivak, Gayatri (2010). Pode o subalternso falar? Belo Horizonte: UFMG.

Vergueiro, Viviane (2016). Por inflexões decoloniais de corpos e identidades de gênero inconformes: uma análise autoetnográfica da cisgeneridade como normatividade (Tese de mestrado). Universidade Federal da Bahia, Salvador, Brasil.

Virilio, Paul (1999). A bomba informática. São Paulo: Estação Liberdade.

Virilio, Paul (2015). Estética da desaparição. Rio de Janeiro: Contraponto. 